\title{
A Novel Method of Voltage Sag and Swell Estimation for Power System Applications
}

\author{
${ }^{1}$ Vetrivel, A., ${ }^{2}$ Jovitha Jerome and ${ }^{3}$ N. Malmurugan \\ ${ }^{1}$ Research Scholar, Anna University, Chennai, India \\ ${ }^{2}$ Department of Elrctronics and Instrumentation, PSG Coolege of Tech, Coimbatore -641 004, India \\ ${ }^{3}$ Department of Research and Development. Mahendra Group of Institutions, Tiruchengode- 637503, India
}

Received 2012-01-29, Revised 2012-12-27; Accepted 2013-07-04

\begin{abstract}
This study presents four simple mathematical models to build the voltage shape with the knowledge of few parameters and detects voltage sag and swells accurately. Fourier series, cubic polynomial, Rational functions and Sum of Sin functions are used in this study to model the voltage profile. A new algorithm is developed to detect sag or swell in all the four models. The voltage estimation due to cubic polynomial has more voltage error and then rational function. The sum of sine function and Fourier series functions does accurate voltage estimation. Errors due to various functions are also tabulated for one electrical cycle. The performance of each method has been compared with other to know the effectiveness of different models and their results are presented.
\end{abstract}

Keywords: Dynamic Voltage Restorer (DVR), Voltage Sag and Swell, Fourier, Cubic Polynomial, Rational and Sum of Sine Functions

\section{INTRODUCTION}

Power quality has become the main interest by the power systems research community. Voltage sags and swells are mainly causing severe damage and down time in the power systems. Voltage Sag (dip) a decrease to between 0.1 and $0.9 \mathrm{pu}$ in rms voltage or current at the power frequency for durations of 0.5 cycles to $1 \mathrm{~min}$ and Swell is an increase to between $1.1 \mathrm{pu}$ and $1.8 \mathrm{pu}$ in $\mathrm{rms}$ voltage or current at the power frequency durations from 0.5-1 min (Bollen, 2000). Table 1 highlights the Categories and Characteristics of Power Systems Electromagnetic Phenomena (Dugan et al., 2003). These sags and swells mainly due to turn on/turn off operations of supply lines and flow of inrush currents during starting of different loads (Dugan et al., 2003). These turn on/turn off can happen either from supply or load side. Sometimes Lightning strikes and EMI can cause momentary sags/swells acc. Numerous solutions have been identified and proposed to mitigate sags and swells wherein a dynamic voltage restorer is one which injects a voltage in series with the supply lines and when any sags voltage sag mitigation by an advanced static VAr and swells are detected. Experimental investigation of

compensator has been well discussed in (Wang et al., 1998). Mostly, the rms voltage measurement method is used to detect the sag and swell before any mitigation is employed. The man drawback of the RMS voltage measurement is that the RMS voltage would be measured through voltage sensors and fed to the ADC of the microcontroller or DSP to convert them into digital and use the data based on the old data which is system dependent. The disadvantages associated with the rms method are discussed in (Xiangning et al., 2000; Tunaboylu et al., 1998).

Table 1. Typical duraion and magnitudes of diffrenet power disturbances

\begin{tabular}{llll}
\hline $\begin{array}{l}\text { Categories } \\
\text { Instantaneous }\end{array}$ & & $\begin{array}{l}\text { Typical } \\
\text { duration }\end{array}$ & $\begin{array}{l}\text { Typical } \\
\text { magnitude }\end{array}$ \\
\hline \multirow{5}{*}{ Momentary } & Sag & $0.5-30$ cycles & $0.1-0.9 \mathrm{pu}$ \\
& Swell & $0.5-30$ cycles & $1.1-1.8 \mathrm{pu}$ \\
& Interruption & $0.5-3 \mathrm{sec}$ & $<0.1 \mathrm{pu}$ \\
& Sag & $0.5-3 \mathrm{sec}$ & $0.1-0.9 \mathrm{pu}$ \\
& Swell & $0.5-3 \mathrm{sec}$ & $1.1-1.8 \mathrm{pu}$ \\
& Interruption & $3 \mathrm{sec}-\mathrm{min}$ & $<0.1 \mathrm{pu}$ \\
& Sag & $3 \mathrm{sec}-1 \mathrm{~min}$ & $0.1-0.9 \mathrm{pu}$ \\
& Swell & $3 \mathrm{sec}-1 \mathrm{~min}$ & $1.1-1.8 \mathrm{pu}$ \\
\hline
\end{tabular}

Corresponding Author: Vetrivel, A., Research Scholar, Anna University, Chennai, India 
Also power quality Surveys shows that voltage sags are considered as the dominant factor affecting power quality (Goldstein and Speranza, 1982). Also in (Naidoo and Pillay, 2007), authors have used rapid sag detection through the use of a nonlinear adaptive filter wherein authors claimed that the filter has an ability to track the amplitude of the sag in real time which would be highly useful for sag and swell mitigation. A novel sag detection method for the line-interactive Dynamic Voltage Restorer (DVR) has been presented in (Bae et al., 2010). Here is the study which discusses different methods to make the voltage shape and then to detect the voltage sags and swells at different operating conditions.

The study is organized as follows: Fistly necessity of initial voltage measurement and existing methods of sag and swell detectionare presented. Subsequently, a description mathematical modeling of Fourier, Gaussian, Cubic polynomial and Sum of sine functions are presented. The voltage sag and swell detection algorithm are presented in further. The results and discussions and its performance evaluation of different methods is presented next and finally Conclusion is presented.

\section{MATERIALS AND METHODS}

\subsection{Necessity of Initial Voltage Measurement}

Voltage measurement is an essential step to develop the mathematical model for the voltage profile. In this research, a 3 phase power quality analyzer was used to measure the voltage over one electrical cycle which would be used to model different mathematical equations.

The measured voltage for two electrical cycles is shown in Fig. 1 and its corresponding data is tabulated in Table 2 Also voltage was recorded for $5 \mathrm{~min}$ duration which is shown in Fig. 2.

\subsection{Mathmatical Modeling}

Mathematical model is a description of any physical system using mathematical language. The process of developing mathematical equations for the systems is called as mathematical modeling. In this study four different mathematical models developed for a voltage profile which can be used to detect the Voltage sags and swells.

\subsection{Fourier Series}

The Fourier series is a sum of sine and cosine functions that is used to describe any periodic signal which can be represented in either the trigonometric form or the exponential form. Since the voltage signal is in the form of periodic nature, here we used the trigonometric Fourier series form shown Equation 1:

$$
y=a_{0}+\sum_{i=0}^{n} a_{i} \cos (n \omega x)+\sum_{i=0}^{n} b_{i} \sin (n \omega x)
$$

Where:

a0 $=$ A constant (intercept) term

$\omega=$ The fundamental frequency of the signal

$\mathrm{N}=$ The number of terms (harmonics) in the series

Real time acquired value in Fig. 1 were used to model the Fourier series equation for the voltage and the same is presented as Equation 2:

$$
y(x)=1.19 e^{-7}-2.152 e^{-6} \cos (0.3142 x)+236 \sin (0.3142 x)
$$

Table 2. Voltage from real time measurement

\begin{tabular}{lc}
\hline Time in $\mathrm{m} \mathrm{sec}$ & Voltage in volts \\
\hline 0 & 0.0000 \\
1 & 72.9280 \\
2 & 138.7173 \\
3 & 190.9280 \\
4 & 224.4493 \\
5 & 236.0000 \\
6 & 224.4493 \\
7 & 190.9280 \\
8 & 138.7173 \\
9 & 72.9280 \\
10 & 0.0000 \\
11 & -72.9280 \\
12 & -138.7173 \\
13 & -190.9280 \\
14 & -224.4493 \\
15 & -236.0000 \\
16 & -224.4493 \\
17 & -190.9280 \\
18 & -138.7173 \\
19 & -72.9280 \\
\hline
\end{tabular}

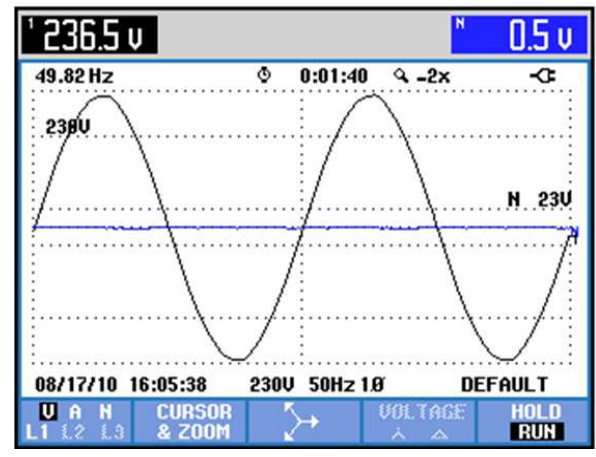

Fig. 1. Voltage for two electrical cycles 


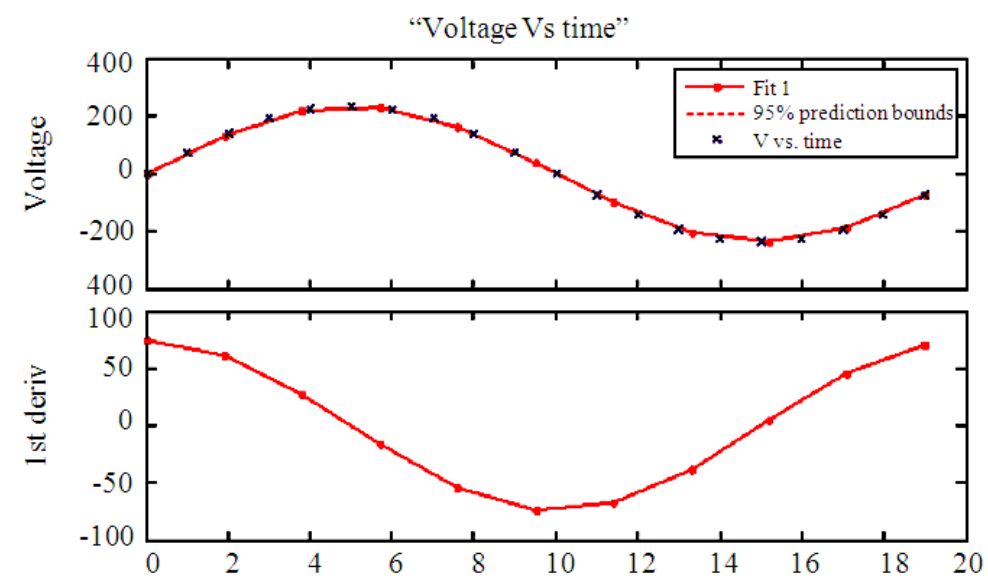

Fig. 2. Voltage profile for one electrical cycle for real time measurement and fourier series function (Top) and its 1st derivative (bottom)

The coefficients of the equation are as follows:

$$
\begin{aligned}
& \mathrm{a} 0=1.196 \mathrm{e}-007(-5.848 \mathrm{e}-006,6.088 \mathrm{e}-006) \\
& \mathrm{a} 1=-2.152 \mathrm{e}-006(-1.743 \mathrm{e}-005,1.312 \mathrm{e}-005) \\
& \mathrm{b} 1=236(236,236) \\
& \mathrm{w}=0.3142(0.3142,0.3142)
\end{aligned}
$$

The Fourier series model developed using equation is plotted along with Voltage profile for one electrical cycle for real time measurement.

\subsection{Cubic Polynomial}

Generally the polynomial models for any physical systems are represented by Equation 3:

$y=\sum_{i=1}^{n+1} p_{i} x^{n+1-i}$

where, $n+1$ is the order of the polynomial $n$ is the degree of the polynomial. The order gives the number of coefficients to be fit and the degree gives the highest power of the predictor variable. In this research, polynomials are third-degree (cubic) polynomial is used and same is given by the linear model as Equation 4:

$y=0.6819 x^{3}-20.28 x^{2}+137.7 x-33.75$

The Coefficients of the equation are as follows:

$\mathrm{p} 1=0.6819(0.6241,0.7397)$

p2 $=-20.28(-21.96,-18.61)$

p3 $=137.7(124.2,151.1)$

p4 $=-33.75(-62.52,-4.971)$

Polynomials are often used when a simple empirical model is required. The model can be used for interpolation or extrapolation, or it can be used to characterize data using a global fit.

The Cubic Polynomial model developed using equation is plotted along with Voltage profile through real time measurement for one electrical cycle and its $1 \mathrm{st}$ derivative (bottom) is shown in Fig. 3.

\subsection{Rational function}

Rational models are defined as ratios of polynomials and are generally represented as Equation 5:

$$
y=\frac{\sum_{i=0}^{n+1} p_{i} x^{n+1-i}}{x^{m}+\sum_{i=1}^{m} q_{i} x^{m-i}}
$$

Where:

$\mathrm{n}=$ The degree of the numerator polynomial $\mathrm{m}=$ The degree of the denominator polynomial

In this research, rational function is a function which is termed as degree of the numerator to the degree of the denominator. For example, a quadratic/cubic rational equation is given by Equation 6:

$y=\frac{95.28 x^{3}-2854 x^{2}+19040 x-613.4}{x^{3}-20.2 x^{2}+227 x}$

Coefficients of the rational function are as follows:

$$
\begin{aligned}
\mathrm{p} 1= & 95.28(88.91,101.6) \\
\mathrm{p} 2= & -2854(-3042,-2665) \\
\mathrm{p} 3= & 1.907 \mathrm{e}+004(1.779 \mathrm{e}+ \\
& 004,2.036 \mathrm{e}+004) \\
\mathrm{p} 4= & -613.4(-1308,80.69) \\
\mathrm{q} 1= & -20.2(-20.52,-19.89) \\
\mathrm{q} 2= & 227(216.8,237.1)
\end{aligned}
$$


Vetrivel, A. et al. / American Journal of Engineering and Applied Sciences 6 (2): 233-240, 2013

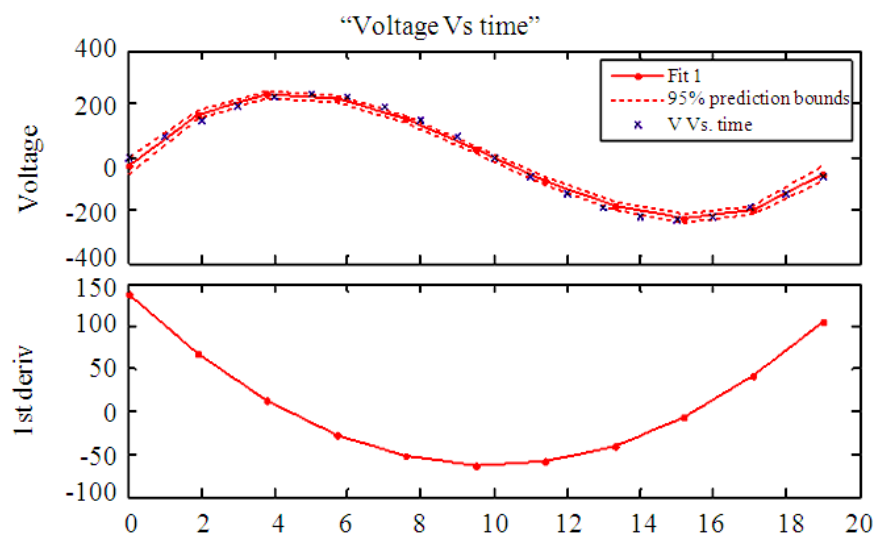

Fig. 3. Voltage profile for one electrical cycle for real time measurement and cubic polynomial function (Top) and its 1 st derivative (bottom)

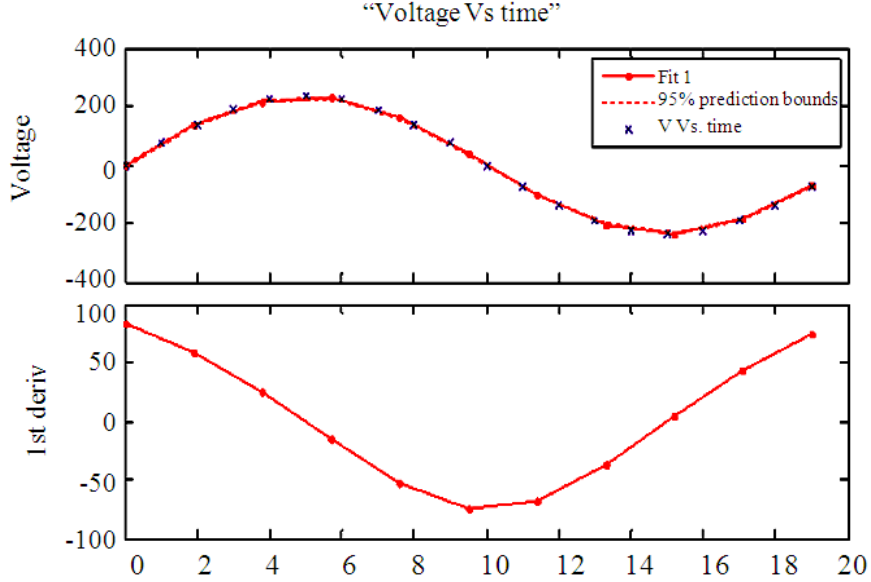

Fig. 4. Voltage profile for one electrical cycle for real time measurement and rational (Top) and its 1st derivative (bottom)

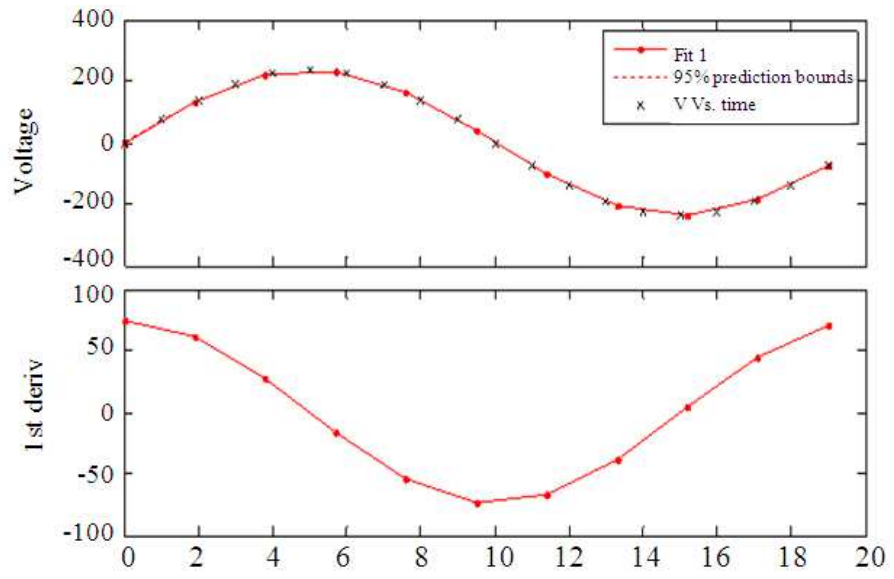

Fig. 5. Voltage profile for one electrical cycle for real time measurement and Sum of sines function (Top) and its 1st derivative (bottom) 


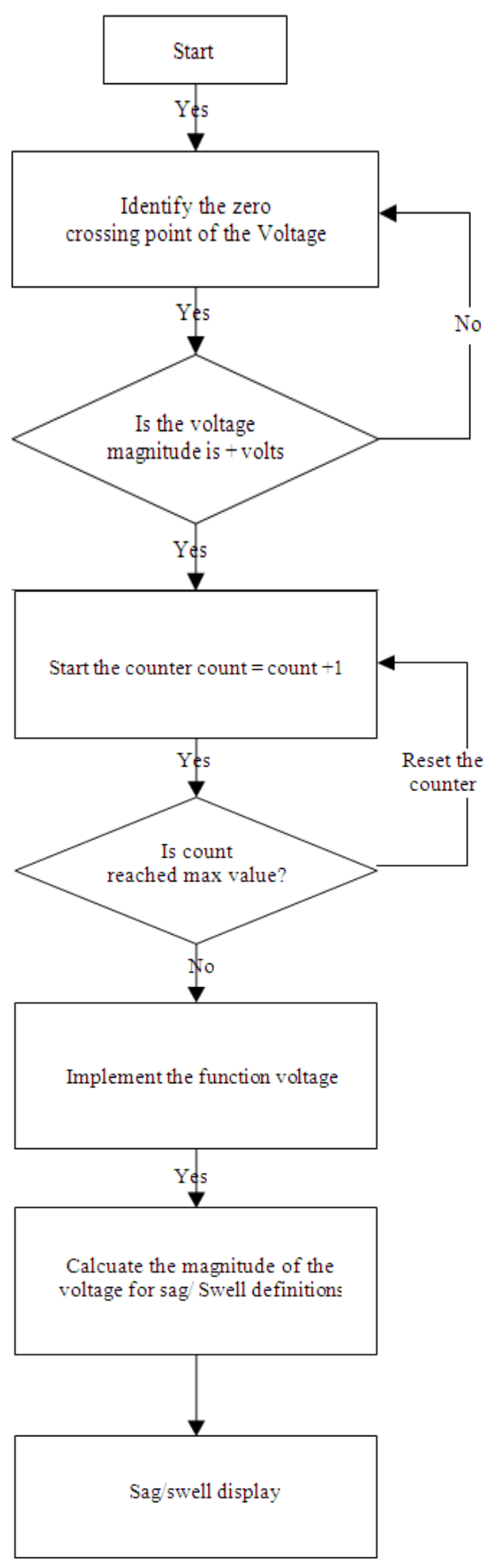

Fig. 6. Sag/Swell detection algorithm
Like polynomials function, rational function are often used in physical system modeling when a simple empirical models are required. The main advantage of rational is their flexibility with data that has complicated structure and the main disadvantage is that they become unstable when the denominator is around zero. The Rational function model developed using equation is plotted along with Voltage profile through real time measurement for one electrical cycle and its $1 \mathrm{st}$ derivative (bottom) is shown in Fig. 4.

\subsection{Sum of sin function}

The sum of sin function model is used for fitting periodic functions and is represented by the Equation 7:

$y=\sum_{i=1}^{n} a_{i} \sin \left(b_{i} x+c_{i}\right)$

Where:

$\mathrm{a}=$ The amplitude

$\mathrm{b}=$ The frequency

$\mathrm{c}=$ The phase constant for each sine wave term

$\mathrm{n}=$ The number of terms in the series

This equation is closely related to the Fourier series that has been described previously in this study. The main difference is that the sum of sin function equation includes the phase constant and does not include a constant (intercept) term Equation 8:

$y=236 \sin \left(0.3142 x-8.99 e^{-9}\right)$ follows:

The coefficients of the Sum of Sin Function are as

$A=236(236,236)$

$\mathrm{b} 1=0.3142(0.3142,0.3142)$

$\mathrm{c} 1=-8.99 \mathrm{e}-009(-7.118 \mathrm{e}-008,5.32 \mathrm{e}-008)$

The Sum of Sin Function developed using equation is plotted along with Voltage profile through real time measurement for one electrical cycle and its $1^{\text {st }}$ derivative (bottom) is shown in Fig. 5.

\section{Algorithm:}

- Identify the zero crossing point of the voltage

- If the voltage magnitude is +ve, move to step number 3 else go to step 1

- Start the counter count $=$ count +1 
- If the counter reached max value, reset the counter and move to step 3 else go to step 5

- Implement the any one of the below functions

- Fourier series

- Cubic functions

- Rational functions

- Sum of sins

- Calculate the sag/swell as per Table 1 and display the results

\subsection{SAG/SWELL detection algorithm}

The step by step procedure for detecting the sag and swell are presented below and its flow chart is given in Fig. 6.

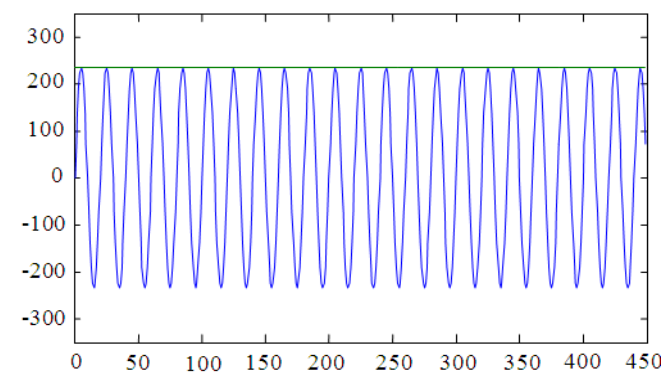

(a)

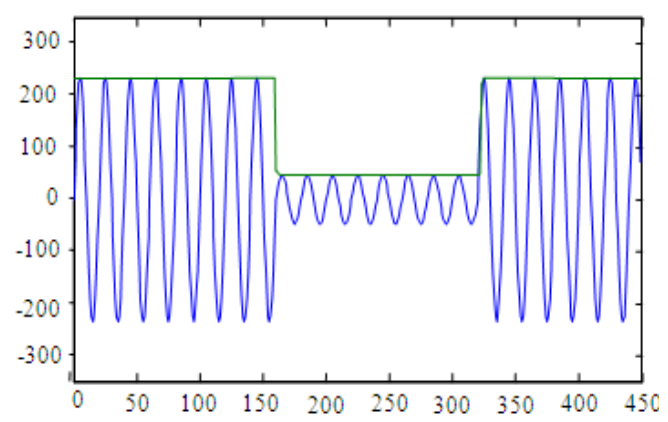

(c)

\section{RESULTS}

The equations for Fourier, Cubic polynomial, Rational and Sum of sine functions for voltage profile has been developed through MATLAB/Simulink modeling Power Quality Analyzer.

From the knowledge of zero crossing voltage information at each electrical cycle and time input, the Fourier, Cubic polynomial, Rational and Sum of sine functions implements the voltage waveform generation. which has been implemented through MATLAB/Simulink. Figure 7 shows the Voltage Vs Time at (a). 236 Volts with no Sag/swell detection (b) 236 volts with $40 \%$ sag (c) 236 volts with $80 \% \mathrm{sag}$, (d) 236 volts with $20 \%$ swell and (e) 236 volts with $60 \%$ swell.

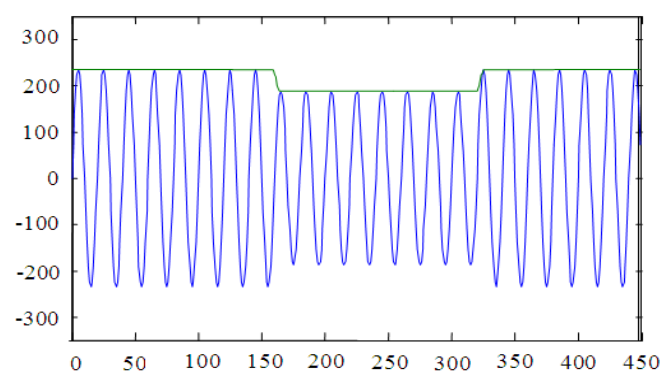

(b)

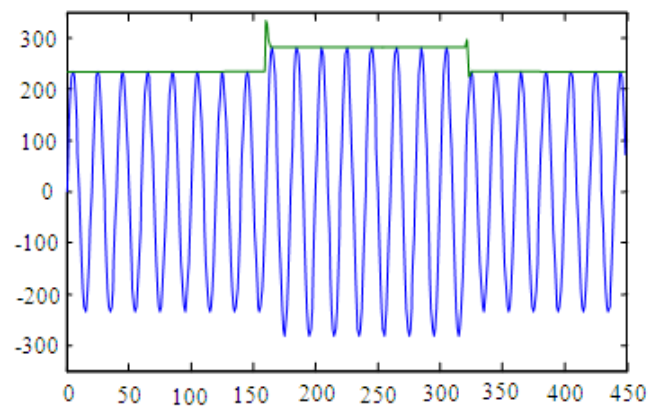

(d)

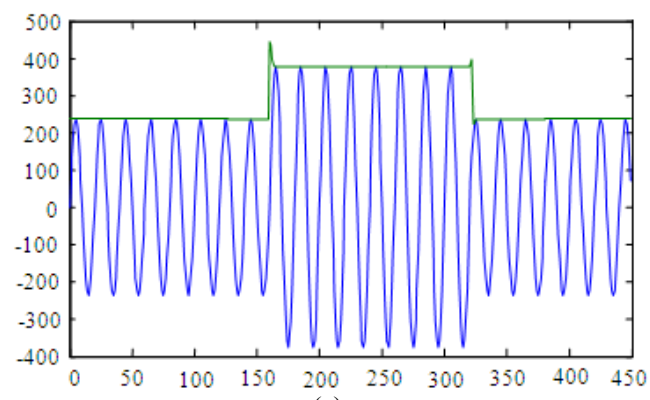

(e)

Fig. 7. Voltage Vs Time (a). 236 volts with no Sag/swell detection (b) 236 volts with $40 \%$ sag (c) 236 volts with $80 \%$ sag, (d) 236 volts with $20 \%$ swell and (e) 236 volts with $60 \%$ swell 
Vetrivel, A. et al. / American Journal of Engineering and Applied Sciences 6 (2): 233-240, 2013

Table 3. Voltage error due to Fourier, cubic polynomial, rational and sum of sine functions

\begin{tabular}{|c|c|c|c|c|c|c|c|c|c|}
\hline $\begin{array}{l}\text { Time in } \\
\mathrm{M} \mathrm{sec}\end{array}$ & $\begin{array}{l}\text { Measured } \\
\text { voltage }\end{array}$ & $\begin{array}{l}\text { Fourier Series } \\
\text { Function (FSF) }\end{array}$ & $\begin{array}{l}\text { Error } \\
\text { due to FSF }\end{array}$ & $\begin{array}{l}\text { Cubic Polynomial } \\
\text { Function (CPF) }\end{array}$ & $\begin{array}{l}\text { Error } \\
\text { due to CPF }\end{array}$ & $\begin{array}{l}\text { Rational } \\
\text { Function (RF) }\end{array}$ & $\begin{array}{l}\text { Error } \\
\text { due to RF }\end{array}$ & $\begin{array}{l}\text { Sum of Sin } \\
\text { Function (SSF) }\end{array}$ & $\begin{array}{l}\text { Error } \\
\text { due to SSF }\end{array}$ \\
\hline 0.0010 & 0.0000 & 0.0741 & 0.0741 & -33.6123 & 33.6123 & -2.6184 & 2.6184 & 0.0741 & -0.0741 \\
\hline 1.0000 & 72.9280 & 72.9372 & -0.0092 & 84.3519 & -11.4239 & 75.5432 & -2.6152 & 72.9372 & -0.0092 \\
\hline 2.0000 & 138.7173 & 138.7329 & -0.0156 & 165.9852 & -27.2679 & 140.9908 & -2.2735 & 138.7329 & -0.0156 \\
\hline 3.0000 & 190.9280 & 190.9450 & -0.0170 & 215.2413 & -24.3133 & 190.8960 & 0.0320 & 190.9450 & -0.0170 \\
\hline 4.0000 & 224.4493 & 224.4612 & -0.0119 & 236.2116 & -11.7623 & 222.5679 & 1.8814 & 224.4612 & -0.0119 \\
\hline 5.0000 & 236.0000 & 236.0000 & 0.0000 & 232.9875 & 3.0125 & 233.7523 & 2.2477 & 236.0000 & 0.0000 \\
\hline 6.0000 & 224.4493 & 224.4315 & 0.0178 & 209.6604 & 14.7889 & 223.1529 & 1.2964 & 224.4315 & 0.0178 \\
\hline 7.0000 & 190.928 & 190.8885 & 0.0395 & 170.3217 & 20.6063 & 191.0226 & -0.0946 & 190.8884 & 0.0396 \\
\hline 8.0000 & 138.7173 & 138.6551 & 0.0622 & 119.0628 & 19.6545 & 139.6751 & -0.9578 & 138.6551 & 0.0622 \\
\hline 9.0000 & 72.9280 & 72.8457 & 0.0823 & 59.9751 & 12.9529 & 73.7062 & -0.7782 & 72.8457 & 0.0823 \\
\hline 10.000 & 0.0000 & -0.0961 & 0.0961 & -2.8500 & 2.8500 & -0.7062 & 0.2672 & -0.0961 & 0.0961 \\
\hline 11.000 & -72.9280 & -73.0286 & 0.1006 & -65.3211 & -7.6069 & -74.4016 & 1.4736 & -73.0286 & 0.1006 \\
\hline 12.000 & -138.7173 & -138.8106 & 0.0933 & -123.3468 & -15.3705 & -140.7897 & 2.0724 & -138.8106 & 0.0933 \\
\hline 13.0000 & -190.9280 & -191.0014 & 0.0734 & -172.8357 & -18.0923 & 192.6480 & 1.7200 & -191.0014 & 0.0734 \\
\hline 14.0000 & -224.4493 & 224.4909 & 0.0416 & -209.6964 & -14.7529 & -225.1718 & 0.7225 & -224.4909 & 0.0416 \\
\hline 15.0000 & -223.0000 & -236.0000 & 0.0000 & -229.8375 & -6.1625 & -235.8617 & -0.1383 & -236.0000 & 0.0000 \\
\hline 16.0000 & -224.4493 & -224.4018 & -0.0475 & -229.1676 & 4.7183 & -224.3462 & -0.1031 & -224.4018 & -0.0475 \\
\hline 17.0000 & -190.9280 & -190.8319 & -0.0961 & -203.5953 & 12.6673 & -191.8816 & 0.9536 & -190.8319 & -0.0961 \\
\hline 18.0000 & -138.7173 & -138.5773 & -0.1400 & -149.0292 & 10.3119 & -140.7494 & 2.0321 & -138.5773 & -0.1400 \\
\hline 19.0000 & -72.9280 & -72.7543 & -0.1737 & -61.3779 & -11.5501 & -73.7115 & 0.7835 & -72.7543 & -0.1737 \\
\hline 20.0000 & 0.0000 & 0.1923 & -0.1923 & 63.1923 & -63.4500 & 6.3973 & -6.3973 & -0.1923 & -0.1923 \\
\hline
\end{tabular}

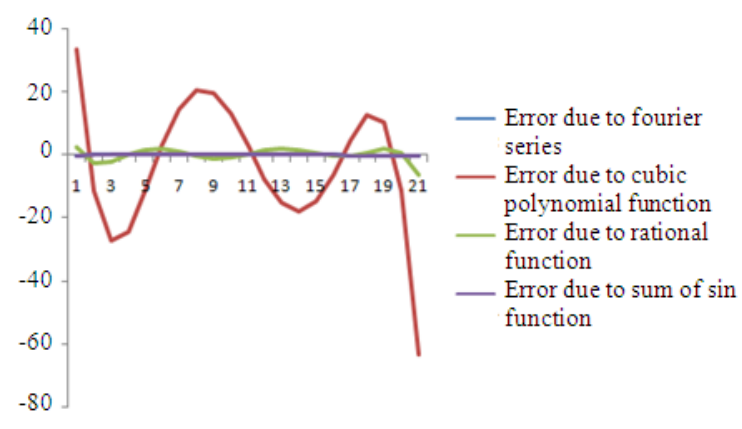

Fig. 8. Voltage Error due to fourier, cubic polynomial, rational and sum of sine functions Vs time for one electrical cycle

\section{DISCUSSION}

It has been observed from the Fig. 8 that sag/swell detector exactly detects the sag and swell information and conveys the message that there is sag and swell. Exists for different operating conditions Fig. 8 shows that Voltage Error due to Fourier, Cubic polynomial, Rational and Sum of sine functions vs. time for one electrical cycle. It has been observed from the Fig. 8 that the voltage estimation due cubic polynomial has more voltage error and then rational function. The sum of sine function and Fourier series functions does accurate voltage estimation. Errors due to various functions are also tabulated in Table 3 for one electrical cycle. It has been observed that the sum of sine function, Fourier series and rational functions are performing better than cubic polynomial. Since these are simple mathematical models, the time consumption implement them in real time is very simple. Also these models can be very well extended to any supply system to achieve the higher reliability and repeatability in sag and swell detections. Its interesting to note that these model requires only few input parameters such as time, voltage and frequency magnitude with zero crossing information. It was found that the developed algorithms detects the sag and swell accurately and quickly within $2 \mathrm{~m} \mathrm{sec}$.

\section{CONCLUSION}

Four new mathematical models have been developed and have been presented and applied to the voltage sag and swell detection of sags in a single phase power system. Also each developed method has been compared with others to find their effectiveness with respect to others. This study conveys that the ability of the each algorithm to detect voltage sags and swells very quickly than the than available methods.

\section{REFERENCES}

Bae, B., J. Jeong, J. Lee and B. Han, 2010. Novel sag detection method for line-interactive dynamic voltage restorer. IEEE Trans. Power Delivery, 251: 1210-1211. DOI: 10.1109/ TPWRD.2009.2037520

Bollen, M.H.J., 2000. Understanding Power Quality Problems: Voltage Sags and Interruptions. 1st Edn., Wiley, New York, ISBN-10: 0780347137, pp: 543, 
Dugan, R., S. Santoso, M.F. McGranaghan and H.W. Beaty, 2003. Electric Power Systems Quality. 2nd Edn., McGrawHill, New York, ISBN-10: 007138622X, pp: 528.

Goldstein, M. and P.D. Speranza, 1982. The Quality of U.S. Commercial AC Power. Proceedings of the International Telecommunications Energy Conference, Oct. 3-6, IEEE Xplore Press, Washington, DC, USA., pp: 28-33. DOI: 10.1109/INTLEC.1982.4793697

Naidoo, R. and P. Pillay, 2007. A new method of voltage sag and swell detection. IEEE Trans. Power Delivery, 22: 1056-1062. DOI: 10.1109/TPWRD.2007.893185

Tunaboylu, N.S., E.R. Jr. Collins and P.R. Chaney, 1998. Voltage disturbance evaluation using the missing voltage technique. Proceedings of the 8th International Conference Harmonics Quality Power, Oct. 14-18, IEEE Xplore Press, Athens, pp: 577-582. DOI: 10.1109/ICHQP.1998.759974
Wang, P., N. Jenkins and M.H.J. Bollen, 1998. Experimental investigation of voltage sag mitigation by an advanced static VAr compensator. IEEE Trans. Power Delv., 13: 1461-1467. DOI: $10.1109 / 61.714772$

Xiangning, X., X. Yonghai and L. Lianguang, 2000. Simulation and analysis of voltage sag mitigation using active series voltage injection. Proceedings of the International Conference Power System Technology, Dec. 4-6, IEEE Xplore Press, Perth, WA., pp: 1317-1322. DOI: 10.1109/ICPST.2000.898160 